\title{
Community survey of shoulder disorders in the elderly to assess the natural history and effects of treatment
}

\author{
P C Vecchio, R T Kavanagh, B L Hazleman, R H King
}

\begin{abstract}
Objective-To assess the natural history and response to treatment of shoulder disorders in a community elderly population.

Method-This community study of shoulder pain in the elderly reviewed patients three years after an earlier prevalence study.

Results-One hundred and eight of the original 136 patients with an identifiable shoulder disorder were available for reexamination. Eighty (74\%) had persisting signs on examination, with persistent symptoms leading to impairment of personal care $(21 \%)$ and household tasks $(27 \%)$, and pain on movement $(34 \%)$. There was no difference between treated and non-treated groups in terms of outcome.

Conclusions-The results of this study serve to confirm and highlight the chronicity of shoulder lesions in this age group and the consequent personal suffering and implications for health care.
\end{abstract}

(Ann Rheum Dis 1995; 54: 152-154)

Shoulder pain in the elderly has been shown to be a common problem, with symptoms or disability in at least $25 \%$ of hospital and community populations. ${ }^{1}{ }^{2}$ A previous survey has shown that the elderly often tolerate their discomfort and do not seek medical advice. ${ }^{3}$ These studies have demonstrated the majority of patient symptoms are caused by soft tissue lesions and are therefore theoretically amenable to treatment. The new General Practitioner contracts in England now require a regular review of the elderly population, ${ }^{4}$ so it is pertinent to review the long term benefits of shoulder pain treatment. ${ }^{5}$ This community study of shoulder pain in the elderly has reviewed patients three years after an earlier study $^{2}$ and evaluated the natural history and long term outcome of treatment in this group of patients.

\section{Patients and methods}

In an earlier study, in which 644 elderly persons were screened for shoulder disorders, ${ }^{2}$ 136 patients were found to have an identifiable intrinsic shoulder disorder. Of these, 83 were given treatment appropriate to the diagnosis, prescribed by the attending physician. Three years later, $108(79 \%)$ were available to be reassessed; 20 had died and the remaining eight either refused assessment or could not be traced. Table 1 lists the original diagnostic criteria (involvement of the glenohumoral joint was recorded as attributable to rheumatoid arthritis or glenhumeral osteoarthritis where appropriate). A structured interview was set out to assess the long term outcome and discover if there was any improvement from treatment received. The nature of the pain (whether present or absent at rest, during the night, on movement, or lying on the affected side) and severity of pain (graded $1=$ mild; 2 = moderate; 3 = severe, for each category) were recorded by a rheumatologist (PV). Restriction of activities, because of residual shoulder problems was documented in relation to personal care, dressing, cooking, housework, gardening, and general activities. Examination assessed the pain on resisted movements, the presence or absence of a painful arc, and the range of passive and active abduction using a pendulum goniometer as previously described. ${ }^{9}$ Treatment given to each patient was recorded.

Each response was graded numerically and the $\chi^{2}$ test was used to compare different cohorts statistically within each category if there were sufficient numbers to allow this method of analysis to be applied.

\section{Results}

We reassessed 108 patients from the original 136 (65 female, 43 male) (table 2). Sixty five $(60 \%)$ received treatments which included steroid injections into the subacromial bursa $(34 ; 31 \%)$, combined injections into the subacromial bursa and anterior glenohumoral joint (four; 4\%), acromioclavicular joint injection (seven; $6 \%$ ), physiotherapy alone (18; $17 \%$, and non-steroidal anti-inflammatory agents (two; 2\%). All patients who received injections received one injection only. Forty three patients were not given any specific treatment (12 refused, the condition was thought to settle spontaneously in 13 , and the condition was thought not to be amenable to treatment in 18). There were no differences between the treatment and non-treatment groups in terms of gender, former occupation, and the dominant arm involved. 
Table 1 Diagnostic criteria for shoulder disorders, used in the original survey

Rotator cuff tendinitis ${ }^{6}$

Shoulder pain exacerbated by movement against resistance in one or more of abduction, external rotation, or internal rotation. Although active range of movement of the joint was limited by pain, passive range of motion remained approximately normal.

Rotator cuff rupture ${ }^{6}$ Chronic rotator cuff rupture was diagnosed if there was marked difficulty in initiating abduction, with weakness and limitation of movement. Pain was usually experienced toward the end of the active range of movement.

Rotator cuff impingement ${ }^{6}$

Rotator cuff impingement alone was considered to be present if there was a painful arc on abduction above $80^{\circ}$, often with the inability to overcome it, and some limitation of passive in addition to active abduction but without the features of the other shoulder conditions described above.

Frozen shoulder

Marked restriction of all active and passive movements, with external rotation reduced by at least $50 \%$ of normal in the absence of bony restriction.

Acromioclavicular join osteoarthritis $^{7}$

Localised pain and tenderness in the region of the AC joint, with a high arc of pain on abduction and with localised pain on joint stressing manoeuvre.

Milwaukee shoulder syndrome

(apatite-related shoulder arthropathy)
Diagnosed in the presence of a large cool shoulder effusion and combined features of rotator cuff rupture and glenohumeral arthritis.
A total of 80 patients $(74 \%)$ had persisting signs of their condition three years after initial diagnosis. Of these, $72(67 \%)$ had either not improved or worsened with respect to shoulder pain and functional impairment when compared with the previous assessment, with persistent symptoms leading to impairment of personal care in $23(21 \%)$ and household tasks in $29(27 \%)$, and pain on movement in 37 $(34 \%)$. Treatment did not seem to influence these symptoms and their subsequent disability as there was no statistical difference between those who had received treatment and those who did not $(p=0.77)$. When steroid treatment was considered separately there was no obvious difference between steroid treated and non-steroid-treated groups in the rotator cuff tendinitis, rupture or impingement groups, or in those with acromioclavicular osteoarthritis. In view of the small numbers in each diagnostic category, however, no separate statistical assessment could be performed.

Rotator cuff tendinitis had the best outcome of the different diagnostic categories, $38 \%$ of patients being free of symptoms at follow up; this contrasted with rotator cuff rupture $16 \%$, rotator cuff impingement $27 \%$, and acromioclavicular osteoarthritis $27 \%$. All of the patients with osteoarthritis or rheumatoid arthritis of the glenohumoral joint, frozen shoulder, or Milwaukee shoulder had either

Table 2 Details of patients reassessed three years after the original survey

\begin{tabular}{|c|c|c|c|c|c|c|c|}
\hline & \multirow{2}{*}{$\begin{array}{l}\text { Total } \\
\text { No }\end{array}$} & \multirow{2}{*}{$\begin{array}{l}\text { Persisting } \\
\text { symptoms/ } \\
\text { signs }\end{array}$} & \multicolumn{2}{|c|}{ Treatment } & \multirow{2}{*}{$\begin{array}{l}\text { No clinical } \\
\text { evidence of } \\
\text { shoulder } \\
\text { dysfunction }\end{array}$} & \multicolumn{2}{|c|}{ Treatment } \\
\hline & & & Yes & No & & Yes & No \\
\hline All patients & 108 & $80(74 \%)$ & 47 & 33 & $28(26 \%)$ & 18 & 10 \\
\hline $\begin{array}{c}\text { Rotator cuff } \\
\text { tendinitis }\end{array}$ & 40 & $25(62 \%)$ & 23 & 2 & $15(38 \%)$ & 12 & 3 \\
\hline Rotator cuff rupure & 19 & $16(84 \%)$ & 7 & 9 & $3(16 \%)$ & 1 & 2 \\
\hline $\begin{array}{c}\text { Rotator cuff } \\
\text { degeneration/ } \\
\text { impingement }\end{array}$ & 15 & $11(73 \%)$ & 5 & 6 & $4(27 \%)$ & 3 & 1 \\
\hline $\begin{array}{l}\text { Acromioclavicular } \\
\text { osteoarthritis }\end{array}$ & 22 & $16(73 \%)$ & 7 & 9 & $6(27 \%)$ & 2 & 4 \\
\hline $\begin{array}{l}\text { Glenohumeral } \\
\text { osteoarthritis }\end{array}$ & 5 & $5(100 \%)$ & 1 & 4 & 0 & 0 & 0 \\
\hline Rheumatiod arthritis & 3 & $3(100 \%)$ & 2 & 1 & 0 & 0 & 0 \\
\hline Frozen shoulder & 3 & $3(100 \%)$ & 1 & 2 & 0 & 0 & 0 \\
\hline Milwaukee shoulder & 1 & $1(100 \%)$ & 1 & 0 & 0 & 0 & 0 \\
\hline
\end{tabular}

not improved or worsened from the original assessment.

\section{Discussion}

This study is a follow up of a large group of elderly patients with shoulder disorders identified by a population survey three years previously. Because the survey was conducted in the community, all diagnoses were based on clinical features. Although well recognised clinical diagnostic criteria were adhered to and broad diagnostic groups identified, without supportive investigations (particularly arthrography and MRI scanning) it is not possible to be absolutely certain of the underlying pathology. This does not, however, detract from finding of persisting shoulder pain and functional impairment recorded in this large group of elderly patients with shoulder disorders.

It would seem from this study that treatment of shoulder pain in the elderly in a community setting appeared to have little or no effect on long term prognosis. Also, when the benefit of steroid injections alone was assessed, no long term difference could be detected between the treated groups and untreated patients. While these results are interesting, this study was not designed specifically to assess the effects of the various treatments, in either the short or the long term. This would have involved prospective selection and serial assessment of a group of patients with symptoms of similar duration (in the original cohort this varied from one month to many years) and randomisation to different treatments and matching with controls.

Because of the theoretical risk of rupture of an ageing (and already degenerate) rotator cuff musculature with repeated corticosteroid injections, it was decided from the outset to limit each patient to a single injection. It could be argued that a single corticosteroid injection would be insufficient to achieve an adequate response (and hence influence outcome) in some of the conditions treated, but to our knowledge there is no good published evidence to suggest that this is the case.

Shoulder pain in the elderly is common and leads frequently to disability, ${ }^{1-3}$ and the prevalence and impact of musculoskeletal disorders is important in considering the provision of health services. This follow up study of patients with painful shoulder suggests that shoulder problems persist in this group of patients. New contracts for English General Practitioners emphasise close supervision of our increasingly elderly population. ${ }^{4}$ This group of patients has a high prevalence of musculoskeletal problems which will have implications for the workload on community services, particularly where these disorders are relatively resistant to treatment and causes of significant disability.

This work was supported by the Arthritis Foundation of Australia and the Arthritis and Rheumatism Council, England. We thank Alex McNeil of the Medical Research Council, Biostatistics Unit, Cambridge, for his helpful suggestions and advice regarding the statistical analysis of our data. 
1 Chard M D, Hazleman B L. Shoulder disorders in the elderly (a hospital study). Ann Rheum Dis 1987; 46: 684-7.

2 Chard M D, Hazleman R, Hazleman B L, King R H, Reiss $\mathrm{B}$ B. Shoulder disorders in the elderly (a community B B. Shoulder disorders in the elderly

3 Chakravarty $\mathrm{K} \mathrm{K}$, Webley M. Disorders of the shoulder: an often unrecognised cause of disability in elderly people. $B M F$ 1990; 300: 848-9.

4 Secretary of State for Health, Social Security, Wales and Scotland. A New Contract. London: Her Majesty's Stationery Office, 1989.

5 O'Reilly D, Bernstein R M. Shoulder pain in the elderly. BMF 1990; 301: 503-4.
6 Cyriax J, ed. Diagnosis of soft tissue lesions. Textbook of

orthopaedic medicine. London: Ballière Tindall, 1971.
7 Kessell L, Watson M. The painful arc syndrome: clinical classification as a guide to management. $\mathcal{F}$ Bone foint Surg $\mathrm{Br} 1977 ;$ 59: $166-72$.

8 McCarty D J, Halverson P B, Carrera G F, Brewer B J Kozin F. "Milwaukee shoulder" - association of microspheroids containing hydroxyapatite crystals, active collagenase, and neutral protease with rotator cuff defects. Arthritis Rheum 1981; 24: 464-73.

9 Binder A, Parr G, Hazleman B, Fitton Jackson S F. Pulsed electromagnetic field therapy of persistent rotator cuff tendinitis; a double blind controlled assessment. Lancet $1984 ;$ i: $695-8$. 